\title{
A Case Report on Dapsone Syndrome
}

\author{
Darga Simrun', K Koteshwar ${ }^{1}$, Thamineni Rajavardhan ${ }^{2, \star}$, Mopuri Bhavani², Languluri Reddannal², \\ V Sreedhar ${ }^{3}$
}

${ }^{1}$ Pharm D Student, Balaji College of Pharmacy, Anantapuramu, Andhra Pradesh, INDIA.

${ }^{2}$ Assistant Professor, Department of Pharmacy Practice, Balaji College of Pharmacy, Anantapuramu, Andhra Pradesh, INDIA.

${ }^{3}$ Principal, Balaji College of Pharmacy, Ananthapuramu, Andhra Pradesh, INDIA.

\begin{abstract}
Dapsone is useful for treating a variety of infectious, immunological and hypersensitivity disorders. Commonly encountered adverse effects of this drug include dose unrelated (idiosyncratic) skin hypersensitivity reactions and dose-related haemolytic anemia and methemoglobinemia. Dapsone Hypersensitivity Syndrome (DHS) can be considered as a manifestation of DRESS (Drug Rash with Eosinophilia and Systemic Symptoms) syndrome. DRESS is an adverse reaction that can be seen with the use of many drugs such as dapsone, sulfonamides, allopurinol, cyclosporine, azathioprine, minocycline, antiviral drugs, anticonvulsant and gold salt. This report refers to 45 year old female patient was brought to the hospital with chief complaints of Fever chills and rash all over the body since 1 week. One year prior to current admission she was prescribed with dapsone $100 \mathrm{mg} / \mathrm{day}$ on suspection of leprosy and found the hypersensitivity reaction on usage of dapsone for 4 weeks. We report a case on Dapsone syndrome with skin rashes all over the body and fever and effectively treated with Corticosteroids.
\end{abstract}

Key words: Dapsone syndrome, DRESS syndrome, Hypersensitivity reactions, Prednisolone.

\section{INTRODUCTION}

Dapsone (4,4'-diaminodiphenylsulfone) is useful for treating a variety of infectious, immunological and hypersensitivity disorders. ${ }^{1}$ Commonly encountered adverse effects of this drug include dose unrelated (idiosyncratic) skin hypersensitivity reactions and dose-related haemolytic anemia and methemoglobinemia. Other notable adverse effects include insomnia and psychosis. A rare, potentially fatal idiosyncratic systemic hypersensitivity syndrome- namely Dapsone Hypersensitivity Syndrome (DHS), characterized by fever, skin rash, eosinophilia, lymphadenopathy, hepatic, pulmonary and other systemic manifestations can complicate dapsone therapy, ${ }^{1-5}$ DHS can cause irreversible organ damage or even death if not recognized early and managed properly. ${ }^{2,5}$

Dapsone Hypersensitivity Syndrome (DHS) can be considered as a manifestation of DRESS (Drug Rash with Eosinophilia and Systemic Symptoms) syndrome. DRESS is an adverse reaction that can be seen with the use of many drugs such as dapsone, sulfonamides, allopurinol, cyclosporine, azathioprine, minocycline, antiviral drugs, anticonvulsant and gold salt. ${ }^{6}$ DHS differs from other drug reactions because it can occur after prolonged exposure of offending drug and even up to 6 months after exposure. DHS is an idiosyncratic multi-organ disease. It has a frequency of $0.2-0.5 \%$ in patients on dapsone therapy. ${ }^{6}$

\section{Case Report}

A 45 year old female patient was brought to the hospital with chief complaints of Fever chills and rash all over the body since 1 week, Rashes over abdomen (Figure 1) Rashes over hand (Figure 2) and Rashes over face (Figure 3). One year prior to current admission she was prescribed with dapsone $100 \mathrm{mg} /$ day on suspection of leprosy and found the hypersensitivity reaction on usage of dapsone for 4 weeks. On admission she had high grade fever and itching all over the body characterised by rash. She had a toxic look, with generalized skin erythema
DOI: 10.5530/ijopp.12.4.58

Address for correspondence: Dr. Thamineni Rajavardhan, Assistant Professor, Department of Pharmacy Practice Balaji College of Pharmacy, Ananthapuramu-515001, Andhra Pradesh, INDIA.

Phone no: +919533260926

Email Id: rajavardhana2@gmail. com

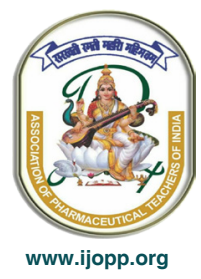




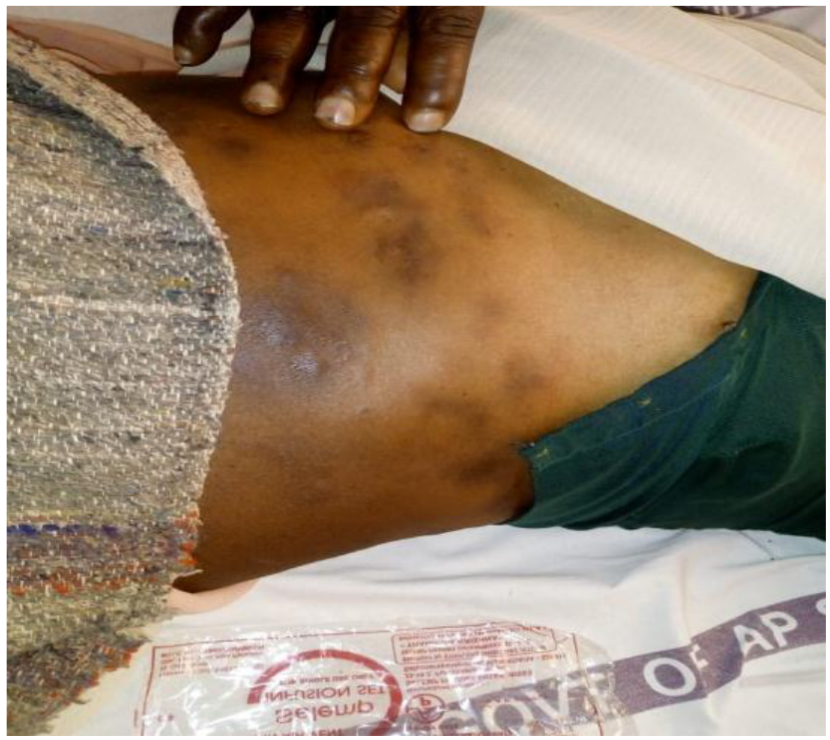

Figure 1: Erythematous lesions abdomen.

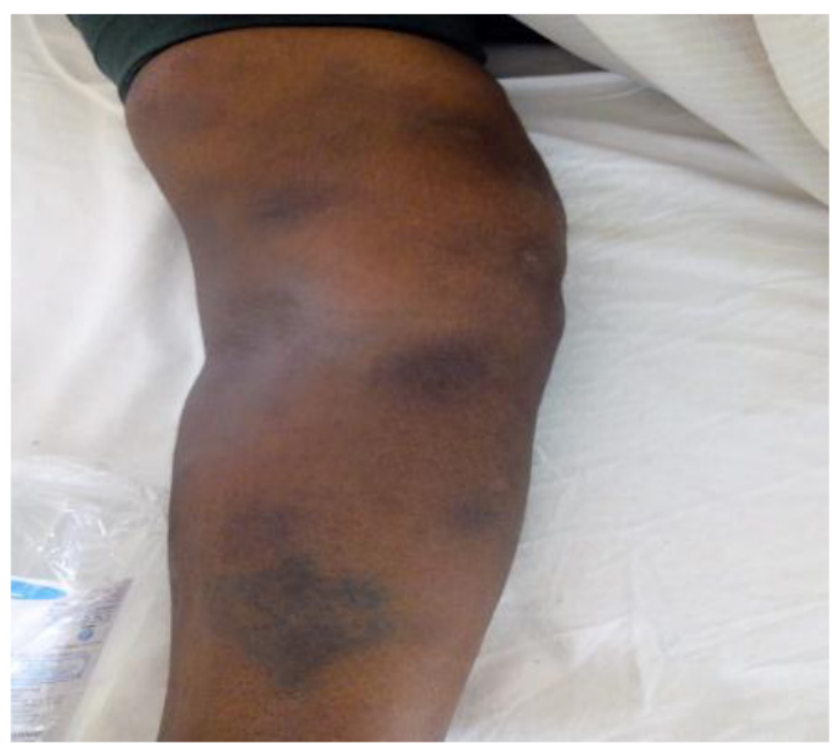

Figure 2: Erythematous lesions on hand.

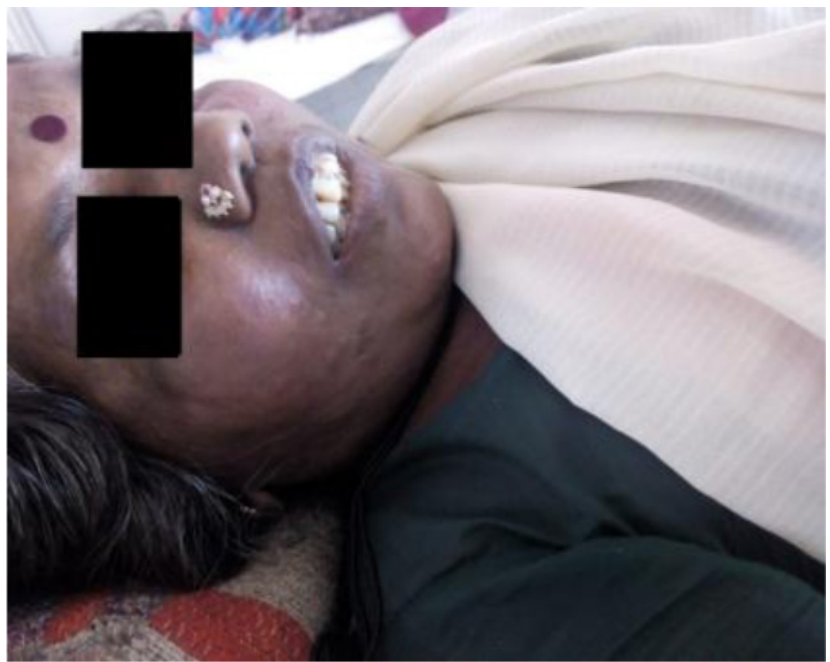

Figure 3: Erythematous lesions on face. and extensive scaling. The therapy was initiated with Prednisolone $5 \mathrm{mg} /$ day and the patient did not respond to the therapy. Empirical broad-spectrum antibiotic cover (Azithromycin) was given keeping the possibility of severe sepsis with septic shock, in view of breach in integrity of the skin. The laboratory investigations include complete blood picture haemoglobin 10.6 $\mathrm{gm} / \mathrm{dl}$, erythrocyte sedimentation rate $35 \mathrm{~mm} / \mathrm{hr}$, differential count: Neutrophils- $78 \%$, Lymphocytes- $12 \%$, Eosinophils- $10 \%$.

\section{DISCUSSION}

DHS can develop several weeks to as long as six months after treatment initiation and the reported incidence ranges from $0.5 \%$ to $3 \% .{ }^{1}$ The diagnosis of DHS is based on clinical findings of fever, skin rash, lymphadenopathy, hepatitis and other systemic features, ${ }^{7}$ along with history of antecedent dapsone exposure. Skin biopsy findings are non-specific. In the present case, the diagnosis was based on typical clinical manifestations following 3 weeks of dapsone intake, after excluding other drug exposures and closes differential diagnoses-namely viral hepatitis, rickettsial infections, CMV, EBV infections, complicated malaria, leptospirosis and was further supported by prompt response to systemic steroids. Rechallenge with dapsone is not recommended, as it can be hazardous. Differences in dapsone metabolism, which affect the production and detoxification of its reactive metabolites might be responsible for differential susceptibility of people to the adverse effects of dapsone. ${ }^{8}$ The inter-individual variability in the metabolism of dapsone by $\mathrm{N}$-hydroxylation to hydroxylamine's by the hepatic microsomal cytochrome P-450 system has been implicated in the haematological toxicity $^{8}$ (methemoglobinemia, haemolytic anaemia and agranulocytosis) but its role in determining the risk of DHS is unclear. ${ }^{1}$

Our case had all the features of dapsone syndrome. Her symptoms appeared within four weeks of starting of dapsone. She had fever and exfoliative dermatitis.

The management involves prompt discontinuation of dapsone, systemic steroids (oral Prednisolone $1 \mathrm{mg} / \mathrm{kg} /$ day or intravenous methyl Prednisolone in equivalent doses) with supportive care. ${ }^{9}$ Gradual tapering of Prednisolone (over more than a month) is recommended considering the persistence of dapsone in the body up to 35 days. ${ }^{9}$ Mortality as high as $12-23 \%$ has been reported in severe DHS. ${ }^{5}$ Thus, a high index of suspicion for early diagnosis, along with prompt treatment is needed. No reliable test capable of predicting the risk for DHS has yet been reported; however, we recently identified a genetic allele, 
HLA-B*13:01, that is significantly associated with DHS among patients with leprosy. According to the literature, patients with viral Hepatitis $(\mathrm{B}, \mathrm{E})$ are at increased risk for the development of DHS, suggesting the need to perform a screening test for hepatitis B before starting dapsone. ${ }^{9-11}$

\section{CONCLUSION}

Generally, DHS is a self-limiting drug reaction and most patients recover following cessation of dapsone therapy and starting treatment with oral corticosteroid. Mortality was reported to be $12-23 \%$ in severe DHS. Physicians, dermatologists, rheumatologists and leprologists prescribing dapsone for various clinical conditions should be aware of potentially fatal DHS to ensure timely diagnosis and appropriate management.

\section{ACKNOWLEDGEMENT}

The authors are thankful to Dr. Narsimha Reddy and the staff of Government General Hospital, Department of General Medicine, Department of Pharmacy Practice, Balaji College of Pharmacy, Anantapuramu.

\section{CONFLICT OF INTEREST}

The authors declare no conflict of interest.

\section{ABBREVIATIONS}

DHS: Dapsone hypersensitivity syndrome; DRESS: Drug Rash with Eosinophilia and Systemic Symptoms; CMV: Cytomegalo Virus; EBV: Ebola virus.

\section{SUMMARY}

Dapsone is useful for treating a variety of infectious, immunological and hypersensitivity disorders. Dapsone can cause several adverse effects, the most serious being Dapsone Hypersensitivity Syndrome (DHS), which is potentially fatal. DHS can develop several weeks to as long as six months after treatment initiation. Commonly encountered adverse effects of this drug include skin hypersensitivity reactions. Management involves prompt discontinuation of dapsone, oral Prednisolone/ intravenous methyl Prednisolone in equivalent doses with supportive care recommended.

\section{REFERENCES}

1. Vinod K, Arun K, Dutta T. Dapsone hypersensitivity syndrome: A rare lifethreatening complication of dapsone therapy. Journal name??? 2019.

2. Chalasani P, Baffoe-Bonnie H, Jurado R. Dapsone Therapy Causing Sulfone Syndrome and Lethal Hepatic Failure in an HIV-Infected Patient. Southern Medical Journal. 1994;87(11):1145-6.

3. Itha S, Kumar A, Dhingra S, Choudhuri G. Dapsone induced cholangitis as a part of dapsone syndrome: A case report. BMC Gastroenterology. 2003;3(1):21.

4. Leslie K, Gaffney K, Ross C, Ridley S, Barker T, Garioch J. A near fatal case of the dapsone hypersensitivity syndrome in a patient with urticarial vasculitis. Clinical and Experimental Dermatology. 2003;28(5):496-8.

5. Pandey B, Shrestha K, Lewis J, Hawksworth R, Walker S. Mortality due to dapsone hypersensitivity syndrome complicating multi-drug therapy for leprosy in Nepal. Tropical Doctor. 2007;37(3):162-3.

6. Puri AS, Gupta R, Ghoshal UC, Khan E, Aggarwal R, Nail SR. Hepatic injury in sulfone syndrome: Hepatitis or cholestasis?. Indian J Gastroenterol. 1995;14(1):20.

7. Allday E, Barnes J. Toxic Effects of Diaminodiphenyl-Sulphone in Treatment of Leprosy. The Lancet. 1951;258(6675):205-6.

8. Coleman M. Dapsone toxicity: Some current perspectives. General Pharmacology: The Vascular System. 1995;26(7):1461-7.

9. Knowles S, Shapiro L, Shear N. Reactive Metabolites and Adverse Drug Reactions: Clinical Considerations. Clinical Reviews in Allergy and Immunology. 2003;24(3):229-38.

10. Zhang FR, Liu H, Irwanto A, Fu XA, Li Y, Yu GQ, et al. HLA-B*13:01 and the dapsone hypersensitivity syndrome. N Engl J Med. 2013;369(17):16208. [PubMed]

11. Chogle A, Nagral A, Soni A, Agale S, Jamadar Z. Dapsone hypersensitivity syndrome with coexisting acute hepatitis E. Indian J Gastroenterol. 2000;19(2):85-6. [PubMed] 